\title{
New Considerations in the Input Filter Design of a Three-Phase Buck-Type PWM Rectifier for Aircraft Applications.
}

\author{
Marcelo Silva, Nico Hensgens, Jesús Oliver, Pedro Alou, Óscar García, and José A Cobos \\ Centro de Electrónica Inductrial \\ Universidad Politécnica de Madrid \\ Madrid, Spain \\ Email: marcelo@silvas.cl
}

\begin{abstract}
An EMI filter for a three-phase buck-type medium power pulse-width modulation rectifier is designed. This filter considers differential mode noise and complies with MIL-STD$461 \mathrm{E}$ for the frequency range of $10 \mathrm{kHz}$ to $10 \mathrm{MHz}$. In industrial applications, the frequency range of the standard starts at $150 \mathrm{kHz}$ and the designer typically uses a switching frequency of $28 \mathrm{kHz}$ because the fifth harmonic is out of the range. This approach is not valid for aircraft applications. In order to design the switching frequency in aircraft applications, the power losses in the semiconductors and the weight of the reactive components should be considered. The proposed design is based on a harmonic analysis of the rectifier input current and an analytical study of the input filter. The classical industrial design does not consider the inductive effect in the filter design because the grid frequency is $50 / 60 \mathrm{~Hz}$. However, in the aircraft applications, the grid frequency is $400 \mathrm{~Hz}$ and the inductance cannot be neglected. The proposed design considers the inductance and the capacitance effect of the filter in order to obtain unitary power factor at full power. In the optimization process, several filters are designed for different switching frequencies of the converter. In addition, designs from single to five stages are considered. The power losses of the converter plus the EMI filter are estimated at these switching frequencies. Considering overall losses and minimal filter volume, the optimal switching frequency is selected.
\end{abstract}

Keywords: Three Phase Rectifier, EMI Filter, High power factor.

\section{INTRODUCTION}

The input filter in a PWM rectifier system has three purposes: 1) to ensure sinusoidally shaped input currents by filtering the switching-frequency harmonics; 2) to attenuate the electromagnetic interference with other electronic systems; 3 ) to avoid susceptibility to electromagnetic emissions from surrounding systems and itself [1], [2], [3]. While designing an EMI filter for a power electronic system, the applicable EMI standards need to be considered.

Typically in industrial applications, the standard to comply with is CISPR 22 class B [4]. The frequency range considered by this standard reaches from $150 \mathrm{kHz}$ to $30 \mathrm{MHz}$. In [1], [5], systems with a switching frequencies $\left(f_{s}\right)$ of $28 \mathrm{kHz}$ and $18 \mathrm{kHz}$ respectively have been designed. These $f_{s}$ have been chosen because they are sufficiently higher in comparison with the grid $(50$ or $60 \mathrm{~Hz})$. In addition, the first, second, third, fourth,

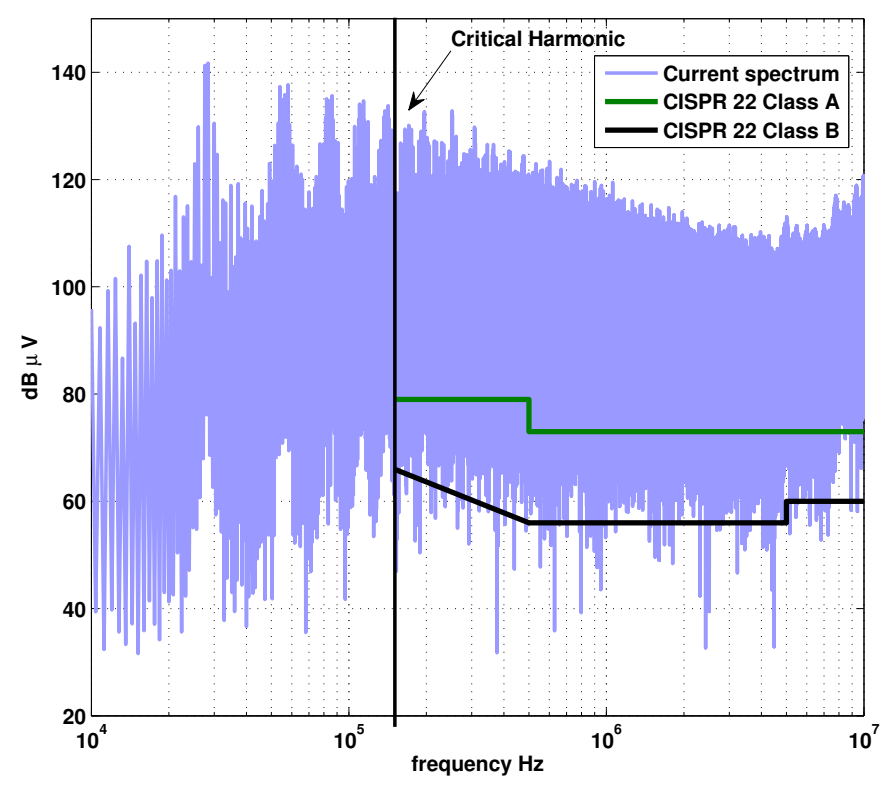

Fig. 1. Spectrum current using $28 \mathrm{kHz}$ switching frequency

and fifth harmonic of the $f_{s}$ are out of the range of CISPR 22 class B; thus, the first harmonic to consider in the input filter design is the sixth harmonic at $168 \mathrm{kHz}$ (when $f_{s}=28 \mathrm{kHz}$ ). This can be seen in the fig 1 .

This work introduces new considerations in the input filter design for a three-phase buck-type pulse-width modulation rectifier (fig. 2(a)) for aircraft applications. In this application the standard to comply with is MIL-STD-461E [6]. This standard is more restrictive than the CISPR 22, regulating a wider range of frequencies from $10 \mathrm{kHz}$ to $10 \mathrm{Mhz}$. Fig. 2(b) shows the limits for MIL-STD-461E, CISPR 22 class $\mathrm{A}$, and CISPR 22 class B. Due to the frequency range of the MIL-STD-461E and the fact that switching frequencies below $10 \mathrm{kHz}$ would not be an optimal design, the rectifier switching frequency must be inside of the range. Therefore, the input filter must be designed in order to attenuate the switching frequency. 


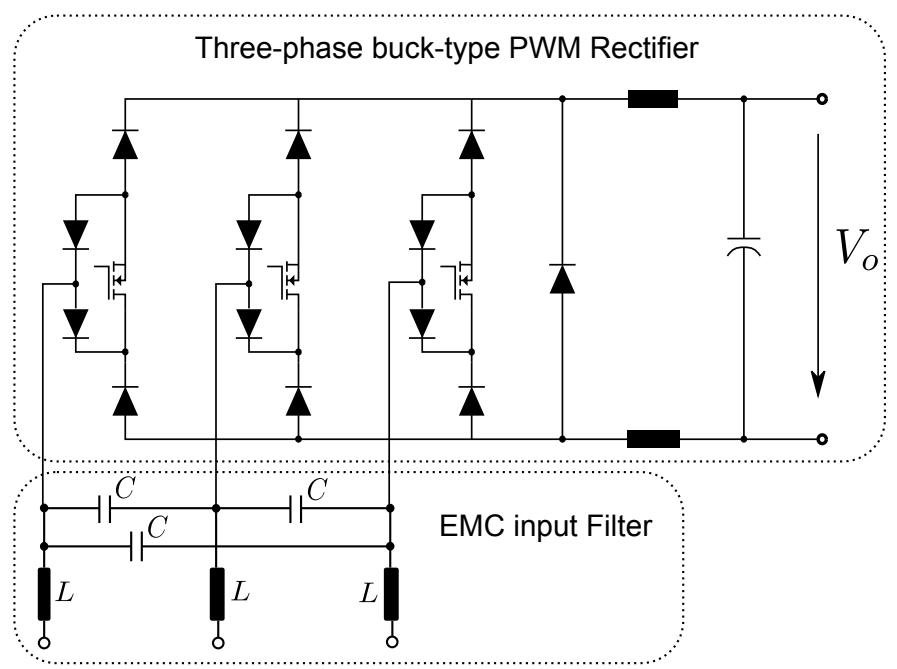

(a)

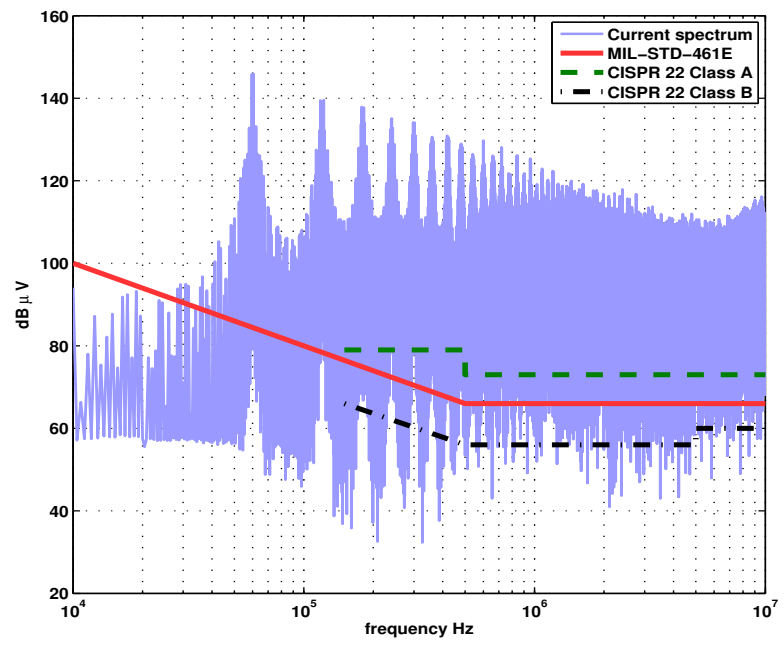

(b)

Fig. 2. (a) Three-phase buck-type PWM rectifier Topology and EMI input Filter, (b) Current spectrum of the rectifier at 3.3kW without input filter

\section{DESIGN OF THE INPUT FILTER}

\section{A. Converter Topology}

The EMC input filter is designed for a three-phase, threeswitch, current source (buck-type) PWM rectifier system, fig 2 (a), with sinusoidal input current, direct start-up, and overcurrent protection in case of an output short circuit. In [7] and [8] this topology has been considered for the realization of the input stage of high-power telecommunications rectifier modules. All of these benefits have prompted the authors to introduce this rectifier in aircraft applications.

In this work, a $3.3 \mathrm{~kW}$ system for an aircraft application will be designed.

\section{B. Cutoff frequency of the input Filter}

In order to know the desired attenuation, the topology needs to be simulated without the input filter. Fig 2 (b) shows the measured input current spectrum. This current is measured utilizing a line impedance stabilizing network (LISN).

With a switching frequency $\left(f_{s}\right)$ of the converter at $60 \mathrm{kHz}$, the first harmonic has an amplitude of $146 \mathrm{~dB} \mu \mathrm{V}$ and the MILSTD-461E limit is $85 \mathrm{~dB} \mu \mathrm{V}$. Considering a margin of $6 \mathrm{~dB}$, the required attenuation is $146-85+5$ (Margin $)=66 \mathrm{~dB} \mu \mathrm{V}$. The cut-off frequency as a function of attenuation and the switching frequency is given by:

$$
\begin{gathered}
\omega_{\text {cutoff }}=\frac{1}{\sqrt{L \cdot C}}=\frac{2 \pi \cdot f_{s}}{\sqrt{10^{\mathrm{Att}[\mathrm{dB}] /(20 n)}}} \\
L \cdot C=\frac{10^{68[\mathrm{~dB}] /(20 n)}}{(2 \pi \cdot 60 \mathrm{kHz})^{2}},
\end{gathered}
$$

where $\mathrm{n}$ is the number of the filter stages. Eq. 2 indicates the value of the product $L \cdot C$ as a function of the required attenuation at a certain frequency. To design the inductive and capacitive values, it is necessary to take into consideration the power factor of the rectifier.

\section{Input Capacitor Consideration in industrial application}

In [7] and [9] the input capacitor is designed in order to limit the reactive power of the rectifier. Eq. (3) gives the maximum value for the input capacitor $C$ as a function of the reactive power (in percentage of the nominal power $P_{N}$ ). Usually this power is limited to $(5 . .10 \%)$ of the rated power in order to ensure high power factor.

$$
C \leq \frac{(0.05 \ldots 0.1) \cdot P_{N}}{\omega \cdot U_{N, l-l, r m s}^{2}}=4.96 \ldots 9.92 \mu \mathrm{F},
$$

where $\omega$ is the grid frequency and $U_{N, l-l, r m s}$ is the line to line input voltage (RMS). In aircraft applications, $\omega=$

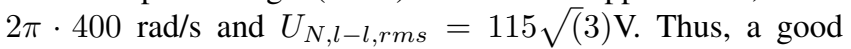
value for the capacitor is $4.7 \mu \mathrm{F}$ because the capacitance is lower than $4.96 \mu \mathrm{F}$, eq. (3). Once the capacitance is fixed, the filter inductance can be calculated with eq.(2); therefore, the inductor value is $3.7 \mathrm{mH}$ using a single stage filter.

Fig. 3 (a) shows the equivalent circuit for the rectifier including the two stage filter impedance seen from the grid. The analytical expression of the impedances are as presented in eqs. (4) and (5)

$$
\begin{aligned}
& Z_{\text {eq1stg }}=\jmath \omega L+\frac{1}{\jmath \omega C+1 / R} \\
& Z_{\text {eq2stg }}=\jmath \omega L+\frac{1}{\jmath \omega C+1 / Z_{\text {eq1stg }}},
\end{aligned}
$$

where $Z_{e q 1 s t g}$ and $Z_{e q 2 s t g}$ are the equivalent impedances for single stage and two stage filters respectively. The resistance corresponding the output power for $3.3 \mathrm{~kW}$ at $115 \mathrm{~V}$ is $R=$ $11.9 \Omega$.

With this filter, the power factor of the system is only 0.66 ( $\left.\cos \left(\angle Z_{\text {eq2stg }}\right)\right)$, but according to eq. (3) should be higher than 0.99 . Therefore, the power factor does not correspond with the design considerations because eq. (3) does not include the 

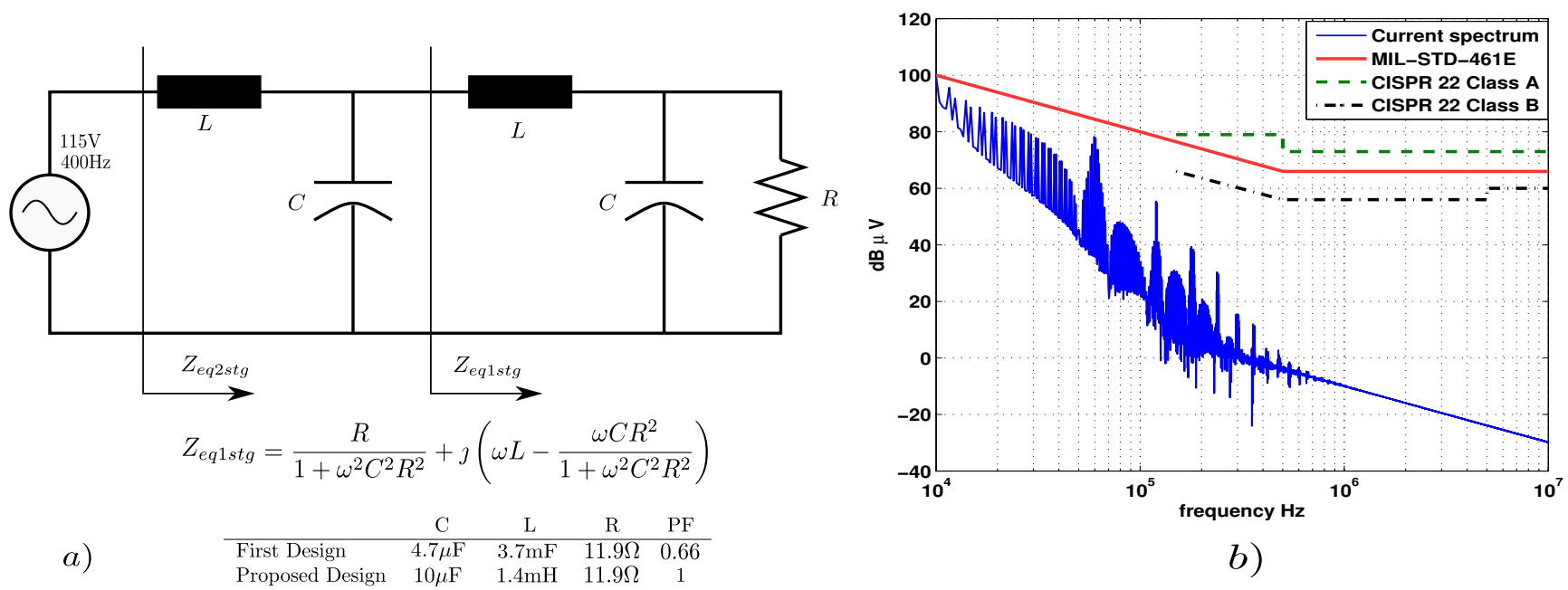

b)

Fig. 3. (a) Equivalent circuit per phase for the rectifier including the input filter seen from the grid. (b) Current spectrum using the proposed filter.

effect of inductor, which can be neglected for a grid frequency of 50 or $60 \mathrm{~Hz}$. However, in aircraft applications the grid is $400 \mathrm{~Hz}[10]$; at this frequency the effect of the inductor can not be neglected anymore.

\section{Proposed Consideration for the input capacitor}

In order to know the influence of the single stage $L-C$ filter on the power factor, the real and the imaginary part of the impedance needs to be considered separately according to eqs. (6) and (7),

$$
\begin{aligned}
& \Re\left\{Z_{\text {eq1stg }}\right\}=\frac{R}{1+(\omega \cdot C \cdot R)^{2}} \\
& \Im\left\{Z_{\text {eq1stg }}\right\}=\omega L-\frac{\omega C}{R^{-2}+\omega^{2} C^{2}} .
\end{aligned}
$$

The unity power factor is obtained when $\Im\left\{Z_{\text {eq1stg }}\right\}=0$. With this condition, and the cut-off frequency being as it is in eq. (1), the filter component is as presented in eqs. (8) and (9)

$$
\begin{aligned}
& C=\frac{1}{R \sqrt{\omega_{\text {cutoff }}^{2}-\omega^{2}}} \\
& L=\frac{1}{\omega_{\text {cutoff }}^{2} C} \cdot
\end{aligned}
$$

Thus, the power factor of the rectifier is unity using a single stage input filter. In addition, if $(\omega \cdot C \cdot R)^{2}<<1$ (this applies when the capacitance is in the order of $\mu \mathrm{F}$ ), the equivalent impedance for the single stage filter is approximately $R$ $\left(Z_{\text {eq1stg }} \approx R\right.$ ). If $Z_{\text {eq1stg }} \approx R$, then $Z_{\text {eq2stg }} \approx Z_{\text {eq1stg }}$ according to eqs. 4 and 5 , and $\Im\left\{Z_{\text {eq2stg }}\right\}=\Im\left\{Z_{\text {eq1stg }}\right\}=0$. Therefore, independent of the amount of the filter stages, when designing the filter according to eqs. (8) and (9), the power factor at full power is unity.

Using this proposed design method, the filter capacitance and inductance are $C=10 \mu \mathrm{F}$ and $L=1.4 m H$. In comparison with the classical design, the proposed design is smaller due to the inductor value. Fig. 3 (b) shows the current spectrum of the rectifier including the designed input filter. The current spectrum complies with the MIL-STD-461E in all the frequencies of the range.

\section{E. Power factor depending on the power demand of the load}

The Three-Phase Buck-Type PWM Rectifier is a two quadrant converter; when the input voltage is positive, the input current is positive and when the input voltage is negative the input current is negative. In addition, the rectifier is controlled in order to obtain sinusoidal wave form currents proportional to the input voltage. For this reason, the rectifier has a resistive behavior at low frequencies (grid frequency), and cannot deliver or absorb reactive power. Because of this, the power factor depends on the input filter and the power demand of the load.

In principle, the filter was designed in order to obtain unitary power factor at full power $(3.3 \mathrm{~kW})$. The black line in fig 4 (a) shows the behavior of the power factor in full range of the power demand; however, from $1.65 \mathrm{~kW}$ to $3.3 \mathrm{~kW}$ the power factor is relatively high (higher than 95\%). On the other hand, if the filter is designed at $1.65 \mathrm{~kW}$, the range of the high power factor increases from $2.5 \mathrm{~kW}$ to $3.3 \mathrm{~kW}$. This can be seen in the red line in fig 4 (a). If the filter is designed at $330 \mathrm{~W}$, the range is reduced from $165 \mathrm{~W}$ to $670 \mathrm{~W}$, showed with the blue line in fig 4(a). The figs 4 (b) and (c) show the same curves for three and four stage filters respectively. The high power factor range increases with the number of stages in the filter. In low power demand, the power factor is inevitably low because the equivalent resistance of the rectifier is neglected in comparison with the impedance of the input filter; thus, the system is practically reactive.

In order to have high power factor in the wide range of the power demand, the input filter has to be designed in half of the nominal power (in this case $1.65 \mathrm{~kW}$ ). However, generally the power factor is measured at full power; therefore, in this 


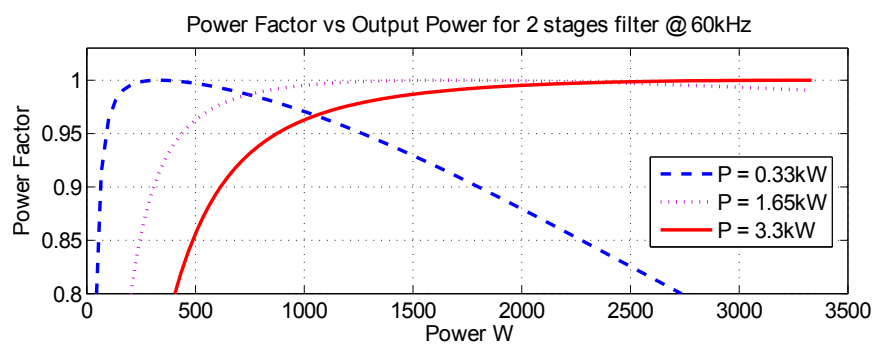

Power Factor vs Output Power for 3 stages filter @ 60kHz

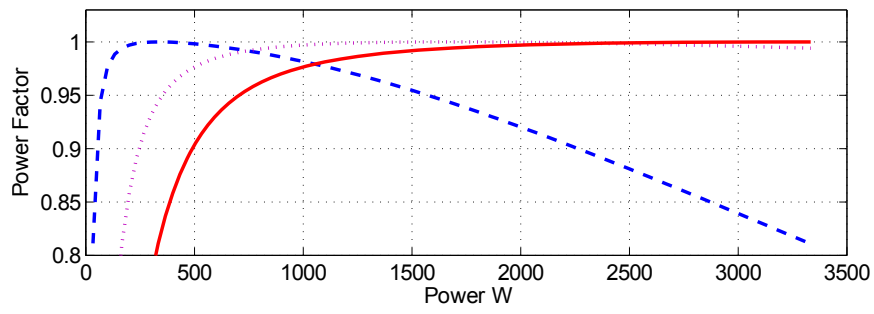

Power Factor vs Output Power for 4 stages filter @ 60kHz

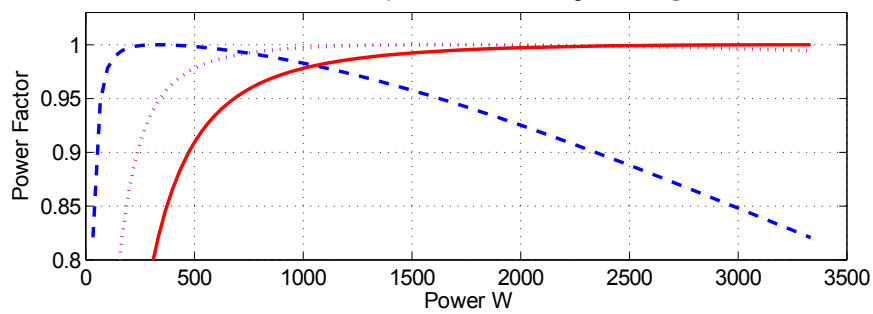

Fig. 4. Power factor depending to the power demand. (a) for two phase filter, (b) for three phase filter, (a) for four phase filter.

paper, the filter is designed in order to obtain unitary power factor at full power $(3.3 \mathrm{~kW})$.

\section{APPLICATION TO THE OPTIMIZATION OF THE INPUT FILTER}

In [1] the switching frequency for this topology is selected at $28 \mathrm{kHz}$ because the fifth harmonic $(140 \mathrm{kHz})$ is out of the standard range $(150 \mathrm{kHz}-30 \mathrm{MHz})$. However, in aircraft applications this method of hiding the switching frequency harmonies below the standards frequency range can not applied because the MIL-STD-461E starting at $10 \mathrm{kHz}$.

The switching frequency will be determined by the tradeoff between weight and power losses, for that the weight of the filter and the losses are going to estimated for different switching frequencies; thus, to obtain a design with a good balance between size and losses.

\section{A. Weight and Losses estimation of the filter}

For multiple-stage $L C$ filters, the minimum volume is achieved by using the same cut-off frequency for all stages [11]. Table I shows the cut-off frequencies from single to five stages filters for different switching frequencies in order to comply with MIL-STD-461E.

Filters with single to five stage are designed using equations (1), (8), and (9). Then, with the inductance and capacitance values from resulting from these cut-off frequencies, the size and weight of the different filter solutions can be estimated.

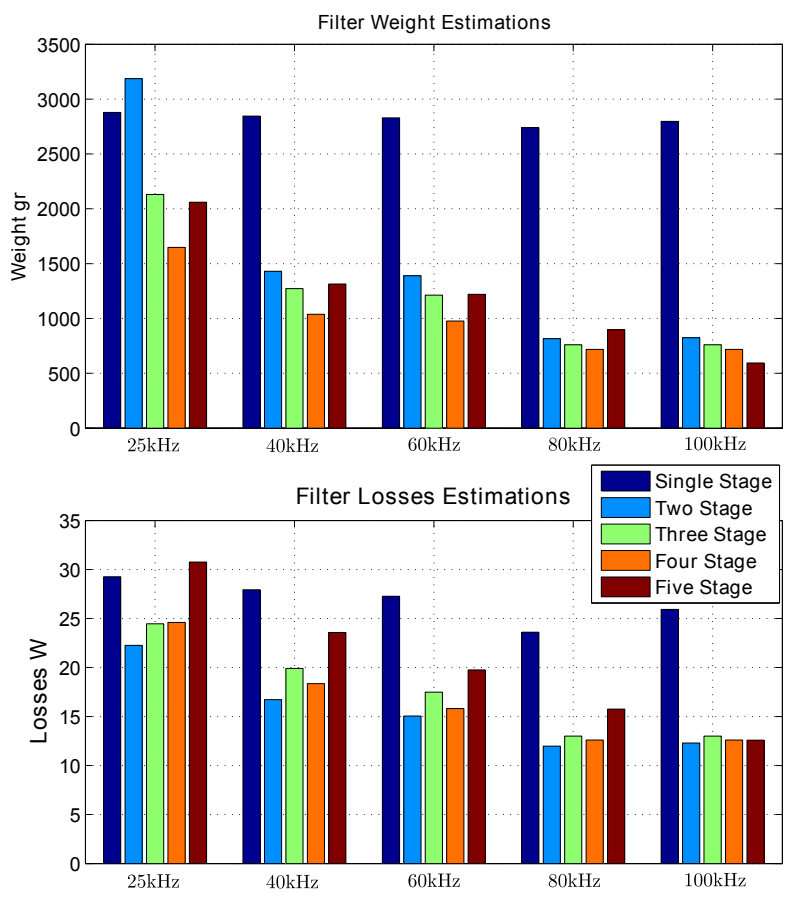

Fig. 5. Filter weight and losses estimation for single, two, three, four and five stages.

TABLE I

CUT-OFF FREQUENCY OF THE FILTER FOR SINGLE TO FIVE STAGES AND DIFFERENT SWITCHING FREQUENCIES IN ORDER TO COMPLY MIL-STD-461E.

\begin{tabular}{c|c|c|c|c|c}
\hline cutoff freq & $\mathbf{2 5 k H z}$ & $\mathbf{4 0 k H z}$ & $\mathbf{6 0 k H z}$ & $\mathbf{8 0 k H z}$ & $\mathbf{1 0 0 k H z}$ \\
\hline \hline Single stage & $792 \mathrm{~Hz}$ & $1.0 \mathrm{kHz}$ & $1.2 \mathrm{kHz}$ & $1.4 \mathrm{kHz}$ & $1.6 \mathrm{kHz}$ \\
\hline Two stage & $4.5 \mathrm{kHz}$ & $6.3 \mathrm{kHz}$ & $8.6 \mathrm{kHz}$ & $10.7 \mathrm{kHz}$ & $12.6 \mathrm{kHz}$ \\
\hline Three stage & $7.9 \mathrm{kHz}$ & $11.7 \mathrm{kHz}$ & $16.4 \mathrm{kHz}$ & $20.9 \mathrm{kHz}$ & $25.1 \mathrm{kHz}$ \\
\hline Four stage & $10.6 \mathrm{kHz}$ & $15.9 \mathrm{kHz}$ & $22.7 \mathrm{kHz}$ & $29.2 \mathrm{kHz}$ & $35.5 \mathrm{kHz}$ \\
\hline Five stage & $12.5 \mathrm{kHz}$ & $19.1 \mathrm{kHz}$ & $27.6 \mathrm{kHz}$ & $35.7 \mathrm{kHz}$ & $43.7 \mathrm{kHz}$ \\
\hline
\end{tabular}

For the weight estimation, the weight of the magnetic cores and of the wound wire are considered. The weight of the capacitors is neglected, since it is much lower than that of the magnetic components.

For the losses estimation, only the winding losses are considered. The core losses are neglected because they are in the range of $\mathrm{mW}$.

The fig. 5(a) shows the weight estimation results. A single stage filter is not practical because the weight are considerably bigger than two, three, four, and five stage filters. Three, four and five stage filters provide only minimal improvements (if any) compared to two stage filters, and the number of components (and parasitic couplings between components) is much higher and because of that the reliability for a two stage filter is higher. In fig 5(b) the filter losses estimations are shown. The two stage filters have lower losses than the rest of filters for all frequencies. Consequently, a two stage filter appears to be the best solution. 

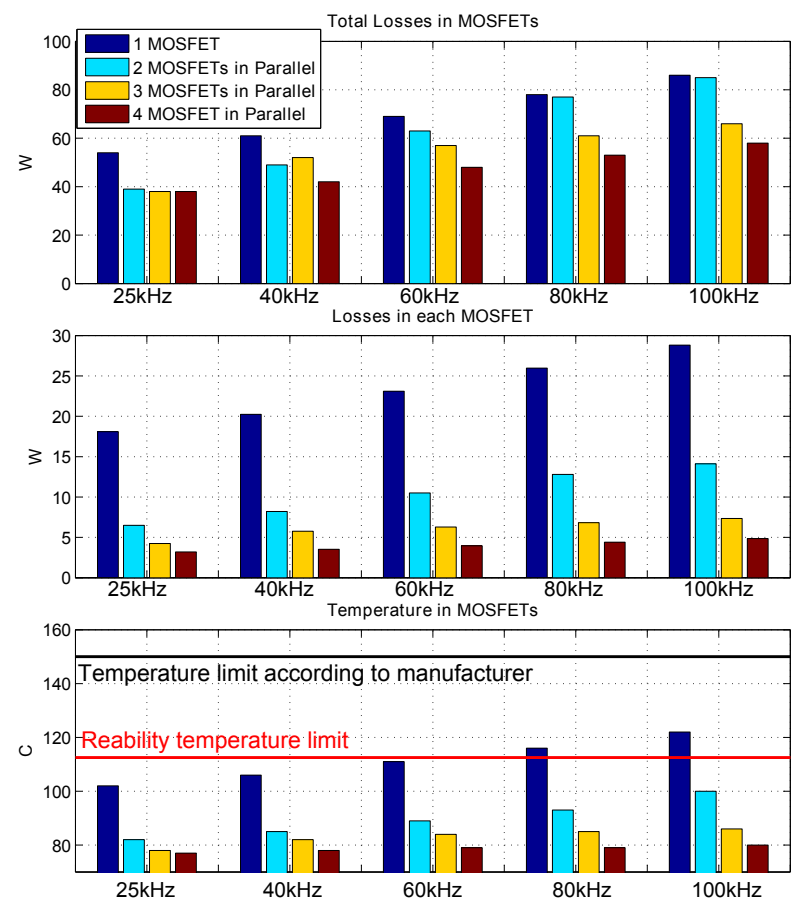

Fig. 6. Power losses in MOSFETs considering since one to 4 MOSFETs in parallel. (a) shows total losses in MOSFETs, (b) shows losses in each MOSFETs and (c) shows the MOSFETs temperature

\section{B. Power losses estimation}

The conducting losses are estimated using the current stresses in the semiconductor [9]. The switching losses are estimated for considered switching frequencies [12] and [13]. These calculations have been carried out using one, two, three, and four MOSFETs in parallel in order to decrease the conducing losses. For every combination of $f_{s}$ and the number of MOSFET in parallel, the optimal device, with respect to the power losses, has been selected from from a database of available components. The power losses of the best MOSFET for every combination switching frequency vs MOSFETs in parallel are shown in the fig. 6(a). The figs 6 (b) and (c) show the power losses per MOSFET and the MOSFET temperature respectively.

For the same number of MOSFETs in parallel, the total losses increase with the switching frequency, due to switching losses. In this case, at low switching frequency $(25 \mathrm{kHz}$ and $40 \mathrm{kHz}$ ) from one MOSFET to two MOSFETs in parallel, the power losses decrease considerably. In the same way, at $80 \mathrm{kHz}$ and $100 \mathrm{kHz}$ from two to three MOSFETs, the total losses decrease.

When increasing the number of MOSFETs in parallel, it not only decreases the losses, but also the losses per MOSFETs and MOSFET temperature decrease drastically. The temperature limit according to manufacture is $150 \mathrm{C}$ degrees, but for reliability considerations the temperature limit used is $75 \%$ of the manufacture limit (red line in the fig. 6(c)). Therefore according to the MOSFET temperature at least it is necessary to use two MOSFET in parallel. In addition, the reliability decreases with the number of MOSFETs; therefore, it is apparent that using two MOSFETs in parallel is the optimum.

\section{Optimum switching frequency}

From the point of view of the filter weight, the highest possible switching frequency is better; however, from the point of view of the power losses in the MOSFETs, lower switching frequency is better. This is a typical tradeoff between efficiency and power density.

In summary, the optimum number of stages of the input filter number is two, and the optimum number of MOSFET in parallel is two. For a two stages filter from $40 \mathrm{kHz}$ to $60 \mathrm{kHz}$, and from $80 \mathrm{kHz}$ and $100 \mathrm{kHz}$, there is no important difference in terms of the weight, fig 5(a); however, the losses for two MOSFETs in parallel increase constantly with the switching frequency, fig 6(a). Therefore, with a switching frequency of $80 \mathrm{kHz}$, the best balance between losses and weight is obtained.

\section{CONCLUSION}

In aircraft applications, the EMI standard to comply is MILSTD-461E. This standard is more restrictive than the CISPR 22 because of its frequency range, and it is not recommendable to consider a switching frequency below the standard range as used in industrial applications.

This work introduces new considerations in the input filter design for a three-phase buck-type pulse-width modulation rectifier for aircraft applications. In this application, the switching frequency has a major impact in the tradeoff between size of the input filter and the power losses more than that of industrial applications because in industrial applications, the switching frequency, the second, third, fourth and fifth harmonics are outside of the standard frequency range.

In addition, in aircraft applications, the classical design method for the input filter considers only grid frequencies of $50 \mathrm{~Hz}$ or $60 \mathrm{~Hz}$; however, when the grid frequency is $400 \mathrm{~Hz}$, the power factor for the system is not close to unity because the industrial approach does not considerer how the inductances affect the system. This work proposes a new consideration in the filter design considering effects of inductances in in order to obtain a unitary power factor at full power, independently of the number of the filter stages.

In order to obtain an optimum switching frequency, the weight and power losses have been estimated for a $3.3 \mathrm{~kW}$ system. According to these estimations, the best trade-off between weight and power losses is at $80 \mathrm{kHz}$ using a two stage filter and two MOSFETs in parallel. As it is presented in this paper the reduction of the filter size from $80 \mathrm{kHz}$ to $100 \mathrm{kHz}$ is marginal in comparison with the increment of the losses. The filter weight at the optimum switching frequency $(80 \mathrm{kHz})$ is a quarter of the filter weight at $25 \mathrm{kHz}$, which is a typical switching frequency in industrial applications. 


\section{REFERENCES}

[1] T. Nussbaumer, M. L. Heldwein, and J. W. Kolar, "Differential mode input filter design for a three-phase buck-type pwm rectifier based on modeling of the emc test receiver," vol. 53, no. 5, pp. 1649-1661, 2006.

[2] H. W. OTT, Electromagnetic Compatibility Engineering, Wiley, Ed. Wiley, 2009.

[3] R. P. CLAYTON, Introduction to Electromagnetic compatibility, second edition. Wiley, 2006

[4] C.I.S.P.R., Comité international spécial des perturbations radioélectriques Std.

[5] A. Stupar, T. Friedli, J. Miniboandck, M. Schweizer, and J. Kolar, "Towards a 99\% efficient three-phase buck-type pfe rectifier for 400 v dc distribution systems," in Applied Power Electronics Conference and Exposition (APEC), 2011 Twenty-Sixth Annual IEEE, march 2011, pp. $505-512$

[6] MIL-STD-461E, Requirements for the control of electromagnetic interference characteristics of subsystems and equipment Std., August 1999.

[7] M. Baumann, U. Drofenik, and J. W. Kolar, "New wide input voltage range three-phase unity power factor rectifier formed by integration of a three-switch buck-derived front-end and a dc/dc boost converter output stage," in Proc. INTELEC Telecommunications Energy Conf. Twentysecond Int, 2000, pp. 461-470.

[8] L. Malesani and P. Tenti, "Three-phase ac/dc pwm converter with sinusoidal ac currents and minimum filter requirements," no. 1, pp. 7177, 1987.

[9] T. Nussbaumer, M. Baumann, and J. W. Kolar, "Comprehensive design of a three-phase three-switch buck-type pwm rectifier," vol. 22 , no. 2 , pp. 551-562, 2007.

[10] G. Gong, M. L. Heldwein, U. Drofenik, J. Minibock, K. Mino, and J. W. Kolar, "Comparative evaluation of three-phase high-power-factor ac-dc converter concepts for application in future more electric aircraft," vol. 52, no. 3, pp. 727-737, 2005.

[11] M. L. Heldwein and J. W. Kolar, "Design of minimum volume emc input filters for an ultra compact three-phase pwm rectifier," in COBEP07. The 7th Brazilian Power Electronics Conference, 2007.

[12] Z. John Shen, Y. Xiong, X. Cheng, Y. Fu, and P. Kumar, "Power mosfet switching loss analysis: A new insight," in Proc. 41st IAS Annual Meeting Industry Applications Conf. Conf. Record of the 2006 IEEE, vol. 3, 2006, pp. 1438-1442.

[13] A. K. Dr. Dušan Graovac, Marco Pürschel, MOSFET Power Losses Calculation Using the DataSheet Parameters, INFINEON, July 2006. 